\title{
Ревитализировала ли лидерскую роль США концепция Барака Обамы об инновационном использовании силы?
}

\author{
Томас Лабуш *
}

\section{Введение}

Соединенные Штаты сформировались как страна, проникнутая уверенностью, что у нее исключительное и объединительное призвание, смысл которого лучше всего сформулирован в ключевой фразе доктрины «Предначертанная судьба» экспансии США на запад в девятнадцатом веке, которая гласит, что США принадлежит предопределенная богом судьба расширить свою территорию на весь Северо-Американский континент и в конечном итоге спасти Старый мир. Тогда как в двадцатом веке эта идеология получила конкретную форму в государстве, которое достигло статуса исключительной сверхсилы, теперь часто предполагается, что первое десятилетие двадцать первого века отражает относительное падение глобального авторитета Соединенных Штатов. Предполагать, что это падение неизбежно, означало бы признание некой формы фатализма, не допускающей ни ту возможность, что США, благодаря их основным преимуществам смогут доказать обратное, ни возможность, что геополитические события в определенный момент могут потенциально предотвратить восход других стран.

Если в период последней администрации Буша Соединенные Штаты часто прибегали к использованию жесткой силы в качестве ответа на определенные проблемы, то при президентстве Барака Обамы некоторые события дают основание предположить, что налицо изменение в подходе США к применению жесткой силы, в более широком смысле - налицо «переделка подхода Америки к остальному миру». ${ }^{1}$

Действительно, многочисленные случаи указывают на то, что сейчас США более умерены, чем можно было бы ожидать, основываясь на опыте предыдущих восьми лет. К примеру, президент Обама в 2010 году объявил о плане вывести войска США из Афганистана в 2014 году. Одновременно, и особенно в 2011 году, Белый дом оказал необычайное давление на Израиль в отношении потенциальных действий последнего против Ирана. ${ }^{2}$ Параллельно этому, события в Ливии во время падения режима Каддафи не показывают бескомпромиссную готовность опи-

\footnotetext{
Томас Лабуш майор французской армии. Эта статья основывается на работе, написанной для 26-го международного курса подготовки по политике безопасности, проведенного Женевским центром по политике безопасности.

1 “Brzezinski Assesses Obama's Foreign Policy," National Public Radio (14 December 2009); аудиофайл доступен на http://www.npr.org/templates/story/story.php?storyId=121426655.

2 Jeffrey Goldberg, "Obama to Iran and Israel: 'As President of the United States, I Don't Bluff'," The Atlantic Monthly (2 March 2012); доступно на http://www.theatlantic.com/ international/archive/2012/03/obama-to-iran-and-israel-as-president-of-the-united-states-idont-bluff/253875/.
} 
раться на силу; так же как действительно то, что «спешка» - последнее слово, которое можно использовать для описания подхода Белого дома к интервенции в Сирию. Конкретно, больший упор был сделан на дипломатию и не привлекающие внимание действия, такие как частое использование ударных беспилотников, точечные удары и переговоры (хотя некоторые действия получили значительное внимание со стороны средств массовой информации). В дополнение к этой необычной позиции появилось желание прояснить отношения с исламом. Декларированный президентом Обама в его речи в Каире в 2009 году, этот более умеренный подход помог в некоторой степени смягчить упреки в сторону американского интервенционизма во всем мусульманском мире.

Обама, которого считают-по крайней мере с европейской точки зрения-гораздо более миролюбивым президентом, чем его предшественник, остался прежде всего Главнокомандующим, который относится к себе как к человеку, выбранному и склонному действовать в защиту интересов США. ${ }^{3}$ Похоже, он рассматривает вариант использования военной силы-как отражено в Стратегии национальной безопасности от 2010 года-через линзу попыток ребалансировать использование силы с тем, чтобы сделать такое решение более неожиданным и менее предсказуемым, чем в прошлом. ${ }^{4}$ В целом, похоже, что Соединенные Штаты приняли новый подход к использованию силы, подход, сочетающий вдумчивую умеренность и рациональное использование военных ресурсов.

Учитывая сказанное выше, основным тезисом этой статьи является утверждение, что новый подход к решению, прибегать ли к силе, даст США возможность ревитализировать свою роль глобального лидера. Возможность такой ревитализации проистекает из трех преимуществ, которые предоставляет этот подход. Вопервых, умеренность смягчит упреки, вызванные предыдущим чрезмерным военным интервенционизмом США. Во-вторых, выход из незаконченных войн, которые являются частью Глобальной войны с терроризмом (ГВТ), позволит перефокусировать энергию на другие основные приоритеты администрации Обамы (экономику, образование). В-третьих, гибкая и адаптивная военная культура может помочь сдерживать или справляться с текущими и грядущими угрозами. Эти основные преимущества будут содействовать восстановлению руководящей роли США во всем мире. Следовательно, в этой статье будет проанализирована док-

3 В этой статье не будет затрагиваться вопрос, в какой степени Обама является единственным, кто принимает решение, когда речь идет об использовании силы. Влияние сильных акторов-институциональных, как Конгресс, или из частного сектора, как бизнес-элита-очевидно, но здесь предполагается, что будучи президентом, Барак Обама дает конечный импульс и осуществляет управление внешней политикой Соединенных Штатов.

Эта стратегия четко отличается от стратегии, обнародованной в 2002 году, которая опиралась на военное превосходство. Представитель США в ООН, Сьюзан Райс, квалифицировала новую стратегию как «драматический отход» от стратегий его предшественников. David E. Sanger and Peter Baker, "New U.S. Security Strategy Focuses on Managing Threats," New York Times (27 May 2010); доступно на www.nytimes.com/2010/05/28/world/ 28strategy.html?ref=world\&_r=1\&. 
трина Обамы путем рассмотрения некоторых главных событий, отражающих его «недекларированную» доктрину внешней политики, прежде чем будет приведена аргументация в пользу создания более гибких военных способностей, которые, если их использовать с умом, вернут США на место глобального политического и морального лидера.

\section{Доктрина, чья лучшая реализация - многообразное ребалансирование}

Поскольку Барак Обама до сих пор не озвучил ясно доктрину использования военной силы, анализ некоторых важных решений, принятых при его президентстве, может помочь раскрыть его «невысказанную» доктрину. Они охватывают ответственный вывод конвенциональных сил из Ирака, массированное использование ударных беспилотников в Пакистане и Йемене, переговоры с некоторыми из фракций движения «Талибан», вербальное сдерживание Израиля от использования силы против Ирана. Чтобы получить систематическое представление об этом перебалансировании, мы можем провести аналогию с разработкой операции и определением линий действия. В целом конечной целью является приобретение определенной свободы действий, которая была сильно ограничена одновременными войнами в Афганистане и в Ираке, войнами, отнимающими ресурсы, которые можно было бы сосредоточить на проектах, которые улучшили бы статус США в мире, а заодно и их безопасность.

\section{Отход от невыполнимых обязательств ...}

Это могло бы быть наименованием первой линии операций. Конкретная проблема, о которой идет речь здесь, это затраты на поддержку войск и ресурсов в Афганистане. Решение окончательно вывести военный персонал из Афганистана, 5 принятое в 2010 году, было принято в полном противоречии со стратегией борьбы с мятежниками, которая требует, наряду с другими условиями для достижения успеха, долгосрочного присутствия, и определенно, не публичного объявления, дающего надежду противнику, для которого время во все большей степени становится союзником. ${ }^{6}$ Независимо от этого, такое решение имеет смысл с точки зрения президента: он не может позволить вести войну, которая до определенной степени в военном отношении, и определенно в плане строительства государства, является ничем иным как тупиком. ${ }^{7}$ Тогда как демократическое развитие страны (и будущее афганского народа), похоже, имеет меньшее значение для Вашингтона, чем десять

5 David Jackson, “Obama: Afghanistan Troop Withdrawal Process to Start Next Year," USA Today (20 November 2010); доступно на http://content.usatoday.com/communities/theoval/post/ 2010/11/obama-holds-nato-news-conference/1\#.UGUJLhjlWL0.

6 Согласно одному исследованию девятнадцати случаев вооруженных восстаний, для достижения успеха в среднем необходимы четырнадцать лет. Seth G. Jones, Counterinsurgency in Afghanistan (Santa Monica, CA: RAND Corporation, 2008).

7 В конце 2007 года, по некоторым оценкам, война в Афганистане стоила США 300 миллионов долларов в день. See Current News Early Bird (17 October 2011). 
лет назад, ${ }^{8}$ Обама все еще одобряет регулярное использование ударных беспилотных самолетов, чтобы и в дальнейшем срывать операции Аль-Каиды. ${ }^{9}$ Это может выглядеть циничным, но это реалистическая позиция (или позиция реалиста). В любом случае, вывод войск США будет пропитан взаимным недовольством, но Соединенные Штаты должны будут сделать так, чтобы их смирение выглядело более-менее почетным, обратив внимание на некоторый достигнутый прогресс, на предоставленную финансовую помощь и на пролитую кровь. ${ }^{10}$ В конечном итоге, одностороннее проведение операции «Джеронимо» в большей степени показало, до каких пределов Обама готов считаться с чувствительностью пакистанцев, чем явилось осуществлением «правосудия для Усамы Бен Ладена». ${ }^{11}$ Все это показывает желание прекратить бесполезную трату энергии там, где результат выглядит сомнительным, и одновременно, продолжить искоренять терроризм, что и было первоначально главным основанием для интервенции в Афганистан. ${ }^{12}$

\section{...сопровождаемый ненадежным равновесием в регионах повыиенного риска ...}

Это оглавление могло бы описывать вторую линию операций, вдоль которой наблюдается перебалансировка. Ближний Восток продолжает находиться в центре внимания США, поэтому Саудовская Аравия остается привилегированным партнером Соединенных Штатов, и похоже, так будет и в будущем. ${ }^{13}$ Саудовская Ара-

8 Стоит задуматься над тем, что произойдет после вывода войск НАТО с теми людьми, которые работали с коалицией. Это может сильно напоминать трагическую судьбу местных жителей, преданных колониальным империям, когда последние ушли из своих колоний: в Алжире около 70000 харкис были убиты после Эвианского соглашения, положившего конец враждебным действиям, и около 200000 «людей с лодок», когда они отчаливали от вьетнамского берега, знали, что в 1976 предстоит другая трагедия.

Удары беспилотных самолетов стали причиной потерь в террористических клетках в пять раз больших, чем те, что были нанесены за весь мандат президента Джорджа У. Буша. Смотри: Victor Davis Hanson, “The President's Chosen Weapon,” Philadelphia Inquirer (13 October 2011); http://articles.philly.com/2011-10-13/news/30275742_1_dronespilotless-aircraft-terrorists.

10 Lt. Col. Daniel L. Davis, "Truth, Lies and Afghanistan - How military leaders have let us down," Armed Forces Journal (February 2012); доступно на www.armedforcesjournal.com/ 2012/02/8904030.

11 Tom Cohen, "Obama Tells Families of 9/11 Victims that 'Justice has been done'," CNN Politics (2 May 2011); доступно на http://articles.cnn.com/2011-05-02/politics/bin.laden.white. house_1_bin-operation-with-extraordinary-courage-defeat-al?_s=PM:POLITICS.

12 Danny Schechter, "Special Ops now Defines the Pentagon's Expanding Wars," Global Research (14 February 2012); доступно на www.globalresearch.ca/special-ops-now-defines-thepentagon-s-expanding-wars.

13 Эти отношения начались на борту корабля США, «Куинси», 14 февраля 1945 года, во время встречи между королем Абдул Азиз ибн Саудом и президентом Франклином Рузвельтом, который возвращался из Ялты. Эта встреча стала началом близкого сотрудни- 
вия остается жизненно важной для США, получая защиту в обмен на регулярные поставки нефти. ${ }^{14}$ Это так же гарантирует беспроблемное получение определенных выгод. ${ }^{15}$ Несмотря на это, регион остается нестабильным. Факт, что Саудовские войска проявили активность в Бахрейне при подавлении шиитских бунтовщиков во время беспорядков в марте 2011 года, хорошо иллюстрирует рискованность регионального разделения. Тогда как мятежники ссылались на объявление войны Саудовской Аравией, ${ }^{16}$ Тегеран снова ухватился за это событие, как возможность осудить тех, кто «ведет себя как Саддам и за кем стоит США». ${ }^{17}$ Еще раз был предотвращен региональный конфликт благодаря посредничеству Государственного департамента США. ${ }^{18}$ Отношения Соединенных Штатов с Израилем тоже являются потенциально опасными. Поддерживаемые общим региональным интересом и потенциально усиленные влиятельным еврейским лобби в США, они становятся еще более сложными и чувствительными, и недавние трения между Тель-Авивом и Вашингтоном являются, может быть, признаком определенного дистанцирования. ${ }^{19}$ Это делает интересным для изучения вопрос, как и почему «осадный менталитет», формирующий на настоящий момент внешнюю политику Израиля, может привести к более или менее рациональному решению, которое за-

чества между США и ваххабитским королевством. Смотри: http://fr.wikipedia.org/wiki/ Abdelaziz_ben_Abderrahmane_Al_Saoud.

14 Lisa Romeo, "Etats-Unis et Arabie saoudite: les liens du pétrole de 1945 à nos jours" [США и Саудовская Аравия: Отношения на основе нефти с 1945 года до сегодняшнего дня], Les clés du Moyen-Orient (n.d.); доступно на http://www.lesclesdumoyenorient.com/Etats-Uniset-Arabie-saoudite-les.html.

15 Они измеряются в нематериальных преимуществах - Саудовская Аравия пользуется статусом стратегического аванпоста в деликатном регионе, а также в виде финансовых прибылей. Эти близкие отношения могут быть ключом к пониманию того, почему США выдали индульгенцию стране, которая воспитала пятнадцать из террористов 9/11.

16 Ethan Bronner and Michael Slackman, "Saudi Troops Enter Bahrain to Help Put down Unrest," New York Times (14 March 2011); доступно на www.nytimes.com/2011/03/15/world/ middleeast/15bahrain.html?pagewanted=all, и "Des troupes saoudiennes à Bahrein, les chiites parlent de guerre," L'Express (14 March 2011); доступно на www.lexpress.fr/actualites/2/ monde/des-troupes-saoudiennes-a-bahrein-les-chiites-parlent-de-guerre_9719 43.html.

Robin Wigglesworth and Simeon Kerr, "Ahmadinejad Condemns Foreign Troops in Bahrain," Financial Times (16 March 2011); доступно на www.ft.com/cms/s/0/5754805a-4e44-11e0a9fa-00144feab49a.html\#axzz27jGsVb3i.

18 Манама в Бахрейне является портом, где сейчас базируется Пятый флот США. Несмотря на это, Саудовская Аравия не смогла воздержаться от спекуляций относительно возможного вмешательства Ирана. Действительно, любая нестабильность в восточных нефтедобывающих провинциях будет на руку Ирану. Смотри Nouriel Roubini, "Middle East Turmoil and Contagion: A Geoeconomic Tsunami for the Global Economy?," Roubini Global Economics (23 February 2011); доступно на http://relooney.fatcow.com/0_New_ 9603.pdf.

19 Тайные операции МОССАД-а, наряду с созданием новой командной структуры, ответственной за «глубокие» операции, начали раздражать Вашингтон. Смотри: "False Flag," Foreign Policy (13 January 2012). 
ведет США в ловушку нежеланного и сомнительного нового военного ангажемента в неподходящих условиях, или на основаниях, которые не могут быть изложены в официальном документе. ${ }^{20} \mathrm{C}$ израильской стороны, акцент на потенциальную угрозу ядерного Ирана может быть придуман, чтобы отвлечь международное внимание от продолжающегося, несмотря на множественные упреки, строительства новых поселений. ${ }^{21}$ Отказ США заплатить 60 миллионов долларов ЮНЕСКО в знак протеста против принятия Палестины не может замаскировать все более свободный тон в замечаниях президента Обамы в сторону Израиля. В то же время можно задуматься, не будет ли иметь революция «Арабской весны» эффект домино на отношения, которые США поддерживает с государствами на Ближнем Востоке.

Уже сложная игра внешней политики в регионе стала еще более запутанной. Перед лицом такой замысловатой ситуации реакция США характеризуется вдумчивостью и умеренностью. Это усиливает ощущение, что у президента Обамы есть соответствующая обстоятельствам доктрина.

\section{... расширенный, чтобы оказать влияние на старейший альянс ...}

И последнее, редуцирование участия США в операциях НАТО звучит как хорошая стратегия для расширения свободы действий Альянса. Хотя пока эта перспектива не подтверждена в терминах будущих решений в рамках пересмотра распределения финансового бремени, ${ }^{22}$ бывший министр обороны, Роберт Гейтс, ясно подчеркнул непропорциональную долю цены операций НАТО, которую платят Соединенные Штаты, и заклеймил европейских союзников, «которые желают, и ждут - не дождутся, чтобы американские налогоплательщики приняли на себя растущий груз обеспечения безопасности, оставленный урезанными оборонными бюджетами в Европе». ${ }^{23}$ Следующий министр обороны, Леон Панетта, передал то же послание более окольным путем, предупредив, что «мы находимся в критиче-

20 "Israel's siege mentality," The Economist (3 June 2010).

21 "Hillary Clinton: Israeli Settlements 'Illegitimate'," ABC News (18 February 2011); доступно на http://abcnews.go.com/Politics/hillary-clinton-israeli-settlements-illegitimate/story?id=129 52834\#.UGpR8hjlWL0. "Israeli Settlements Condemned by Western Powers," BBC News (2 November 2011); доступно на www.bbc.co.uk/news/world-middle-east-15556801. Adrien Jaulmes, "L'UE appelle à enrayer la colonisation en Cisjordanie," Le Figaro (13 January 2012); доступно на www.lefigaro.fr/international/2012/01/13/01003-20120113ARTFIG006 65-1-ue-appelle-a-enrayer-la-colonisation-en-cisjordanie.php.

22 Сокращение бюджетов, влияющее на военные расходы, может быть логичной политикой. В то же время Европу критикуют за уменьшение военных бюджетов. David Morgan, “Gates Criticizes NATO: How Much Does U.S. Pay?," CBS News (10 June 2011); доступно на www.cbsnews.com/2100-202_162-20070541.html.

Там же. 
ском для нашего оборонного сотрудничества моменте». ${ }^{24}$ Очевидно, НАТО находится на перепутье: Соединенные Штаты не будут и дальше постоянно принимать на себя большую часть финансового бремени, тогда как европейские члены Альянса уменьшают свои бюджеты на оборону. ${ }^{25}$ Это просто проявление здравого смысла, и расхожие словечки, такие как «Интеллигентная оборона» и «Объединение и совместное использование», которые направлены больше на экономию, чем на эффективность, могут просто породить у США скептицизм относительно готовности Европы вносить честно свою долю.

Одновременно с этими заявлениями, США выводит одну десятую своих сил, расквартированных в Европе, что и не так уж и много, но показывает уменьшение военного интереса США к этому региону и указывает на потенциальные дальнейшие сокращения. Что более важно, необычайно ограниченные обязательства США на предоставление ресурсов для последней операции НАТО (в Ливии) стало красноречивым сигналом. Из всех причин, что можно было бы перечислить для оправдания весьма скромной роли США в операции против режима Каддафи, Обама указал на «моральную авантюру» под флагом недавней концепции «Обязанности защищать». ${ }^{26}$ Сильное своевременное заявление легитимности западной интервенции, усиленное региональной поддержкой, могло бы позволить более расширенный ангажемент США. Однако, интерес США не был достаточным, чтобы обеспечить больший вклад, чем тот, что они в конце концов сделали. Несмотря на достаточное отражение в средствах массовой информации и на критическую важность предоставленных США ресурсов, уровень поддержки со стороны Вашингтона не идет ни в какое сравнение с обычным вкладом США в операциях НАТО. ${ }^{27}$ И последнее, ливийская авантюра еще раз указывает на предпочтение к прагматизму со стороны США. Они могут продолжить направлять НАТО, занимая удобную позицию «руководства с задней линии», одновременно призывая к большему участию европейских членов НАТО. ${ }^{28}$ Такая роль может помочь ограничить упреки против США, а также поможет избежать фиаско, подобные тем,

24 "Panetta: U.S. Military Can't Make up NATO Shortfalls," msnbc.com (5 October 2011); доступно на www.msnbc.msn.com/id/44782470/ns/us_news-security/t/panetta-us-militarycant-make-nato-shortfalls/\#.UGpQThjlWL0.

25 Andrew A. Michta, "NATO's Last Chance," The American Interest 6:5 (May/June 2011): 5660; доступно на http://www.the-american-interest.com/article-bd.cfm?piece=959.

26 James Traub, "A Moral Adventure - Is Barack Obama as much of a foreign-policy realist as he thinks he is?," Foreign Policy (31 March 2011); available at http://www.foreignpolicy.com/ articles/2011/03/31/a_moral_adventure.

27 Командование операцией было предоставлено адмиралу Джеймсу Д. Ставридису, США.

28 Michael Boyle, "Obama: 'Leading from Behind' on Libya," The Guardian (27 August 2011); доступно на http://www.guardian.co.uk/commentisfree/cifamerica/2011/aug/27/obama-libyaleadership-nato. 
что имели место в Могадишо или Багдаде. ${ }^{29}$ И снова, эта умеренность проистекает от стратегической точки зрения Обамы.

В итоге, похоже, что манера поведения Вашингтона на поле международной безопасности в самом деле эволюировала. Во-первых, используются, или создаются, не все возможности для массированного применения силы. Во-вторых, США больше не чувствуют себя обязанными вмешиваться везде и всюду там, где другие могли бы ожидать этого от них, просто из-за их традиционной склонности к интервенционализму или из-за их военного превосходства. В третьих, если было принято решение рассматривать какой-то вопрос как предмет безопасности, это не означает автоматически скорой готовности к массированному использованию силы. Скорее всего, такое решение будет принято гораздо более рассудительным образом, и может в итоге привести к необычному сочетанию использования мягкой и жесткой силы, применяемых в пропорциях, идущих в разрез с интуицией, основанной на прошлых решениях США по вопросам безопасности.

Очевидно, что президент Обама не хочет, чтобы политический капитал, войска и финансовые ресурсы США были поглощены плохо обдуманными, большими, длительными и дорогостоящими интервенциями. Наоборот, отстранение от некоторых болевых точек внешней политики, или применение традиционных способов их третирования приводит к расширению свободы действий для Вашингтона. Чтобы утвердить свою роль глобального лидера, иногда Соединенным Штатам придется отказываться от использования замечательно эффективного военного инструмента.

\section{Доктрина и усовершенствование военных инструментов путем эффективного использования неочевидного опыта}

Доктрина, которая стремится к максимальному получению преимуществ от использования жесткой силы, ставит некоторые вопросы. Первый вопрос, были ли усвоены все уроки от прошлых случаев применения жесткой силы. Следующий шаг, это убедиться, что уроки прошлого не учитываются только под давлением текущих проблем в настоящем, иначе в будущем, в периоды с меньшим уровнем напряжения, может появиться тенденция просто вернуться к прежней устаревшей доктрине. Стоить рассмотреть в качестве необходимого условия (sine qua non) то, как военная культура ассимилирует такую доктрину. ${ }^{30}$

29 Thomas E. Ricks, Fiasco: The American Military Adventure in Iraq (New York: Penguin, 2006).

30 В рамках этой статьи принимается во внимание то, что область культуры является ключевой для любых других изменений в военной сфере. Поэтому другие элементы, такие как оборудование, метод рекрутирования и т.д. здесь не рассматриваются. 


\section{Подлинное изучение прошлого опыта ...}

Одним из ключевых элементов любой военной доктрины является положение, что приобретенный опыт-уроки прошлого-надо использовать лучшим образом. ${ }^{31}$ За всю военную историю США были идентифицированы множество уроков и мириады книг были написаны для того, чтобы анализировать то, что было сделано в прошлых военных столкновениях. Проблема, может быть, в том, что начиная от Американской революции, через Гражданскую войну и Индейские войны, через Первую и Вторую мировые войны, через интервенции на Филиппины и в Корею, через восстановление Германии и Японии, а так же учитывая опыт в Сомали и в Косово и период до восстановления Ирака, уроки извлекались с той точки зрения, которая практически не ставила под вопрос интеллектуально установившуюся военную культуру и проистекающее из нее настроение умов. Действительно, тем предположением, что человек всегда учится больше на поражениях, чем на победах, похоже, пренебрегали. Поэтому просто возвращение к опыту США во Вьетнаме очень поучительно. Использование термина «Вьетнамский синдром» показывает влияние, которое имела и все еще имеет эта война на военную культуру США.

Вьетнам был сложным случаем, потому что там сочетались конвенциональная война на Севере и одновременно контр-партизанская война, которая велась внутри Южного Вьетнама. ${ }^{32}$ Война велась генеральскими кадрами, которые произошли от поколения полковников, нанесших поражение немецкому Вермахту и японской императорской армии за двадцать лет до этого. Их опыт и культура заставляли их опираться на массированное использование силы, которое оказалось неуспешным $^{33}$ - решение, принятое несмотря на множество противоположных мнений, начиная от советов британских офицеров и до подходов «с нижнего уровня». ${ }^{34}$ Од-

31 «С двумя тысячами лет примеров из прошлого у нас нет никакого извинения, когда мы воюем, не воевать хорошо ...». Т. Е. Лоуренс, письмо к Базилью Х. Лидл-Харт; смотри: Liddell-Hart, Lawrence of Arabia (Boston: Da Capo Press, 1989).

32 Когда говорим о Вьетнаме, мы должны отбросить некоторые популярные представления. Надо, чтобы было ясно, что война во Вьетнаме была частично проиграна из-за того, что велись две одновременные войны: одна против регулярных войск Северного Вьетнама, и другая против Вьетконгского восстания в Южном Вьетнаме. Уже было сказано о расширении масштаба конвенциональных сражений, что коммунисты выбрали этот путь потому, что мятеж на юге близился к неуспеху. Это действительно привело к весенней и летней офанзиве в 1972 году, направленной на «откладывание прогресса умиротворения, намечавшегося в Южном Вьетнаме». В Military Review (October 2006): 90.

33 50 \% бомб, сброшенных США на Вьетнам, упали на Южный Вьетнам. Смотри: А.Ј. Coates, The Ethics of War (Manchester and New York: Manchester University Press, 1997), c. 230 .

34 Подходящее использование опыта британских офицеров, приобретенного в Малайской чрезвычайной ситуации, могло бы помочь генералам США избежать искушения полагаться почти исключительно на бомбардировки и массовый ввод дополнительных войск. Эти подходы «с нижнего уровня» включали среди прочих программу умиротворения 
нако, осведомленность и понимание даже на самом высоком политическом уровне не успели преодолеть влияние доминирующего образа мышления военных. ${ }^{35}$ Более того, одновременность Холодной войны с ее конвенциональной культурой и поражение во Вьетнаме-которое рассматривалось как случайный, ограниченный во времени пример,- -естественно способствовало установлению устойчивой настороженности к неконвенциональным способам ведения войны. ${ }^{36}$ В последнюю очередь, война типа Блицкриг, которая нанесла поражение армиям Ирака в 1990 и 2003, придала этой тенденции дополнительное доверие. Однако, вторая фаза второй Иракской войны, включающая конфликт с разрастающимся мятежом, а так же война, которая идет в Афганистане, оспаривают и являются вызовом этой конвенциональной культуре своими асимметричными угрозами, которые стали новой парадигмой, ${ }^{37}$ так как действия против повстанцев не придерживаются никаких установленных стандартов, в отличии от конвенциональных военных действий. ${ }^{38}$ Речь

ГОПРР (Гражданские Операции и Поддержка Революционного Развития) и подход «стратегических деревень».

35 Относительно свидетельств об этой осведомленности смотри речь президента Джона Ф. Кеннеди в Вест Пойнте 6 июня 1962, предупреждавшего о войне нового типа - «новой по своей интенсивности, древней по своему происхождению ... война путем инфильтрации, а не агрессии, стремящаяся к победе через постепенный подрыв сил и истощение противника, а не через открытое противоборство ...», война, которая потребует «новую стратегию и новый способ подготовки». Доступно на www.youtube.com/watch?v= 7WSHVh-ZtMs.

«Историю армии США во Вьетнаме можно рассматривать как историю личностей, пытавшихся реализовать изменения контр-партизанской доктрины, но которым не удалось преодолеть очень сильную организационную культуру, предрасположенную к конвенциональной доктрине «войны на истощение». John A. Nagl, Learning to Eat Soup with a Knife: Counterinsurgency Lessons from Malaya and Vietnam (Chicago: University of Chicago Press, 2005).

36 Смотри глубокий анализ доктрины США, сделанный Вальтером Е. Кретчиком в Walter E. Kretchik, U.S. Army Doctrine: From the American Revolution to the War on Terror (Lawrence, KS: University Press of Kansas, 2011).

37 Симметрия характеризирует конфронтацию, при которой противоборствующие силы имеют приблизительно одни и те же стандарты в смысле доктрины, размеров и вооружения. Несимметрия относится к типу войны, при которой существуют дисбалансы в одной или нескольких из вышеупомянутых областей. И последнее, асимметрический способ ведения военных действий отражает конфронтацию при которой стиль, стратегии и тактика обеих сторон существенно отличаются. В таком случае замысел состоит в том, чтобы обойти превосходство противника в данных областях. «Коммунистическая стратегия затянувшейся войны оказалась успешной отчасти потому, что она правильно определила общественное мнение как американский центр тяжести». В Jeffrey Record and W. Andrew Terrill, Iraq and Vietnam: Differences, Similarities and Insights (Carlisle, PA: Strategic Studies Institute of the U.S. Army War College, 2004). В основе этих отличий лежат неоднозначные дефиниции таких понятий как сила, победа, поражение, успех, легитимный и воюющий в правовом, культурном и международном смысле.

38 Смотри: Christopher Sims, Fernando Luján, and Bing West, "Both Sides of the COIN: Defining War After Afghanistan," Foreign Affairs (January/February 2012); доступно на 
идет об адаптации к особенностям данного восстания которое само по себе является противодействующим способом военных действий. Поэтому в интеллектуальном плане это гораздо менее комфортабельный способ, чем конвенциональный образ военных действий, потому, что он часто ведет к пересмотру положений, до сих пор считавшихся само собой разумеющимися. Пространство определенных застывших знаний и неоспариваемого оперативного искусства, которые доминировали в военном мышлении, уступают место отсутствию всегда применимых правил, территории, где успех зависит от признания важности контр-интуиции, и где глобальное понимание и инновационность являются главными усилителями эффективности. Опыт, приобретенный военными США в течении последнего десятилетия, сделал возможным появления этой новой школы мышления, что привело к более совершенным подходам к вопросу, как использовать силу. Наиболее видным пионером этого мышления, может быть, является генерал Дейвид Петреус, который, изучив в подробностях опыт Вьетнамской войны, оказался в состоянии сделать так, чтобы квинтэссенция этого травматизирующего опыта не была забыта и потеряна. ${ }^{39}$ В то же время он сумел не пожертвовать своим пониманием текущих условий в угоду историческим знаниям. Это привело к тому, что в своих решениях он всегда ставил ударение на достижение глубокого понимания ситуации до того как предпринимать какие бы то ни было действия, и на предоставлении первенства духу доктрины, чем самой доктрине. Культурная независимость начала приносить дивиденды.

\section{... долюно поощряться текущуими ограничениями}

Изобилие сегодняшних ресурсных ограничений должно помочь этой новой культуре выжить. Однако есть опасность, если доктринальный и интеллектуальный сдвиг, обрисованный выше, является просто реакцией на ситуацию, которая окажется временной. Остается вероятность того, что если текущее стимулирующее давление в ближайшем будущем снизится, основные тенденции старой культуры могут вернуться назад.

С одной стороны, мы можем предположить, что десятилетние войны в Афганистане и в Ираке сформировали военное мышление с акцентом на контр-повстанческие действия, которое в результате может стать доминирующей характеристикой военной культуры. Действительно, лейтенанты и капитаны, которые сражались в Фалудже и боролись за стабилизацию провинции Хелманд, станут полковниками и генералами в 2025 году. С другой стороны, предположение, что с главными новопоявляющимися угрозами будущего лучше всего удастся справиться конвенциональными средствами, указывает на возможное возрождение культуры, которая ставит ударение на конвенциональные способы военных дейст-

www.foreignaffairs.com/articles/136960/christopher-sims-fernando-lujan-and-bing-west/bothsides-of-the-coin.

39 Ген. Мартин Е. Демпси, к примеру, в "Building Critical Thinkers: Leader Development Must Be the Army's Top Priority," Armed Forces Journal 148:7 (February 2011): 12-15. 
вий (и конвенциональное мышление). В то же время, параллельно с развертыванием еще существующих угроз, будь это глобальный терроризм, конвенциональные вооруженные силы, кибератаки, милитаризация Космоса и т.д., будет происходить сокращение военного бюджета США. Все это взывает к введению изменений. До сих пор приоритетом военных расходов США было сохранение боевых способностей при уменьшении войск и активов. ${ }^{40}$

Куда все это приведет, неясно, хотя это может вылиться в преобладание контрпартизанского или конвенционального способа ведения войны в оборонном мышлении США. Как бы то ни было, обладание эффективной военной машины показывает, что основной элемент настоящей силы состоит не в том, чтобы выбрать одно и пренебречь другим, а в сохранении обеих возможностей в живом, реактивном и гибком состоянии. ${ }^{41}$ Достичь этого труднее, чем просто выбрать одно или другое, поскольку это потребует от лидеров открытого ума, развития большей изощренности мысли, чем была нужна при последнем повороте в сторону исключительно контр-партизанской войны. ${ }^{42}$ Если он вознамеривается сохранить положение США, как государства с лучшими военными в мире, президент Обама наверное будет иметь это ввиду. ${ }^{43}$

\section{... и в итоге должно смягчить инерциюю военных}

Изменить или адаптировать менталитет отдельного человека нелегко; изменить менталитет институции еще труднее. Поэтому изменение менталитета военного сословия может являться еще большим вызовом, примеры чего, к сожалению, история демонстрирует нам снова и снова. ${ }^{44}$ Что означает этот урок? Можно принять новую стратегическую политическую доктрину, но ее военная реализация потребует времени, чтобы она просочилась в военные институции и изменила образ мышления отдельных людей.

40 Thomas Donnelly, Phillip Dur, and Andrew F. Krepinevich, Jr., "The Future of U.S. Military Power: Debating How to Address China, Iran, and Others," Foreign Affairs (November/ December 2009); available at www.foreignaffairs.com/ articles/65507/thomas-donnelly-philipdur-and-andrew-f-krepinevich-jr/the-future-of-us-military-power.

41 Как заявил бывший министр обороны США, Роберт Гейтс: «Главным вызовом, следовательно, является то, как сделать так, чтобы приобретенные способности и контр-повстаннические уроки, извлеченные из опыта Ирака и Афганистана, так же как и уроки, которые мы получили в других местах, где мы были вовлечены в нерегулярные военные действия в течении последних двух десятилетий, были институционализированы в оборонном ведомстве». Цитировано в “2008 National Defense Strategy,” Small Wars Journal (31 July 2008).

42 Смотри: Dempsey, "Building Critical Thinkers."

43 Как было заявлено в Национальной оборонной стратегии от 2008 года и отражено в речи о Состоянии союза от 2012 года.

44 Это основной тезис книги Джона Нагла «Учиться есть суn ножсм» (Learning to Eat Soup with a Knife). 
Целое поколение военного персонала проходило свою службу в Афганистане и в Ираке. Тем временем генерал Петреус разработал новую доктрину, предназначенную разрушить «Аль-Каиду» и ее филиалы, и одновременно уменьшить отчуждение от местного населения. ${ }^{45}$ Определенно нелегко восстановить доверие среди этих людей и «завоевать сердца и умы», особенно имея ввиду первоначальные ошибки, которые сделали западные силы в регионе. Независимо от этого, оказалось возможно достичь некоторых успехов. И эти положительные результаты не должны полностью затеняться местными культурными особенностями, которые напоминают нам насколько это трудно - построить централизованную и уважаемую власть там, где гражданское общество еще не созрело достаточно, чтобы принять такое управление. ${ }^{46}$

Полагая, что гибкость должна стать нормой культуры военных США, ее не надо ограничивать только в рамках нынешних контр-террористических кампаний. Разумеется, требуемая гибкость состоит не только в овладевании контр-партизанскими стратегиями, в инновационном их применении и в создании новых. Она состоит и в способности проводить контр-повстанческие операции-и в способности адаптировать подходы, когда это необходимо,-не теряя способности планировать, и в то же время проводить и адаптировать стратегии для действий против конвенциональных угроз. Без сомнения, это является большим вызовом, так как гораздо легче ограничить чью-то компетентность одной или другой областью. Но текущие проблемы безопасности, точно так же, как и те, что могут иметь место в будущем, требуют от военных лидеров более обширных знаний и неослабевающей гибкости ума.

Военные США располагают огромным богатством. Сочетание мощи их вооруженных сил, знаний, приобретенных вследствие опыта последнего десятилетия и их превосходства по всему спектру вооружений, является потенциалом для сохранения статуса прочной и неоспоримой военной силы. Тем не менее, сохранение гибкости и остроты мышления позволит им вести те типы войн, с которыми они в действительности столкнутся, а не те, с которыми они хотели бы столкнуться. Работая, чтобы не стать интеллектуально ограниченными, военные США и дальше смогут считать себя лучшими в мире и смогут служить внешней политике Соединенных Штатов лучшим образом.

Даже если культура военной институции будет лучше приспособлена к условиям, и таким образом обеспечит усовершенствованный потенциал для увеличе-

45 В контр-партизанском подходе ревизированный Полевой устав Cyхопутных войск $C Ш A$, дает больше места размышлению, способности к адаптации, культурной осведомленности и пропорциональности - множеству таких вопросов, что раньше не были обычными в доктрине. Counterinsurgency: The U.S. Army Field Manual, No.3-24 (Washington, D.C.: Department of the Army, December 2006).

46 «Надо помнить, что в течении столетий Афганистан был скорее географическим понятием, чем государством». George Alfred Henty, For Name and Fame; or, Through Afghan Passes (London: Blackie \& Son, 1886); полный текст доступен на: www.gutenberg.org/ dirs/2/1/9/7/ 21979/21979-h/21979-h.htm. 
ния ее эффективности, военную машину можно сделать бесполезной, если политическое руководство будет использовать неправильно ее способности. Разумеется, политические лидеры не должны поддаваться искушению часто полагаться на жесткую силу только потому, что она достигла высокого уровня эффективности. Наоборот, больший успех во внешней политике явится, в конце концов, результатом сочетания рационального использования эффективной военной силы и более тонкого политического чутья. И именно уважение или страх, которые вызывает вооруженная мудрость, и будет сдерживать противника.

\section{Доктрина, чья эффективность в итоге зависит от разумного полити- ческого использования эффективной армии}

Приспосабливание культуры к требуемой мудрости ...

Мудрость, требуемая для использования вооруженной силы подходящим образом, является важнейшим фактором. До самого конца военной фазы второй иракской войны и поражения сил Саддама Хусейна в 2003 году, массовое ангажирование конвенциональных сил было основной характеристикой использования военной силы. Недостатки общих, грубых и скоропалительных подходов к применению военной мощи стали поводом к размышлению. Последнее должно предшествовать всем случаям военного участия потому, что когда войска уже задействованы, менять решение, конечно же, поздно. К примеру, в случае Афганистана в 2001 году можно спросить себя, а не было ли бы более ограниченное, но более острое вмешательство достаточным, чтобы уничтожить «Аль-Каиду» и «Талибан». И даже если бы такое вмешательство потерпело неуспех, все еще оставался бы вариант с вводом дополнительных войск. И наоборот, начальное существенное ангажирование не оставляет никаких альтернатив в случае неуспеха: любое уменьшение количества войск или их полный вывод до того, как будет достигнут существенный успех, будет восприниматься как проявление слабости, а результат интервенции как провал.

Культура становится особенно важной темой для обсуждения, когда принятые решения идут в разрез с традиционной философией нетерпения, агрессивности и высокомерия. ${ }^{47}$ Обаму много раз критиковали за способ участия Соединенных Штатов в операции «Объединенный защитник» над Ливией. Это озвученное разочарование произрастает из нетерпения, которое берет свои корни из двух фактов: то, что Муаммар Каддафи не был объявлен сразу же целью для уничтожения, и то, что ливийский огонь получал пропорциональный и постепенно нарастающий ответ. $^{48}$ Действительно, многие ожидали более крупномасштабного использования

47 Смотри: Robert Kagan, Of Paradise and Power: America and Europe in the New World Or$\operatorname{der}$ (New York: Alfred Knopf, 2003) - книга (и статья на которой она основывается), котораяа породила известную формулировку «Американцы пришли с Марса, европейцы - с Венеры».

48 Некоторые удары против наземных целей откладывались или даже отменялись из-за близости гражданских лиц или просто из-за близости обрабатываемых земель, с намере- 
воздушной мощи для нанесения поражения ливийскому руководству и регулярной армии так скоро, как это возможно. С точки зрения хулителей Обамы, военное участие США должно было быть направлено на устранение Каддафи и на уничтожение его ресурсов. То, что случилось на самом деле, шло в разрез с традиционной моделью ведения войны Соединенными Штатами. Поэтому одобрение президентом Обамой пропорциональной и соразмерной акции европейского типа виделось кое-кому манифестацией слабости или нерешительности. ${ }^{49}$ Однако, конец покровительствуемых режимом убийств и благодарность, выраженная свободными ливийцами после падения диктатуры Каддафи, показали, что ограниченная акция была наиболее мудрым курсом. Подтвердит ли время этот вывод, является отдельным вопросом. Как бы там не было, «руководство с задней линии» или признание наличия недостатков Соединенных Штатов вряд ли будет льстить его американским генералам, но зато поможет успокоить союзников США. ${ }^{50}$

\section{... и соответствующее репозиционирование Ultima Ratio Regum ...}

Когда рассматриваются последствия, которые имеет любое использование военной силы, и особенно драматические последствия неправильного использования, необходимо найти ответ на несколько вопросов: почему, когда и как надо развертывать силы? «Почему» предполагает, что сила является логическим компонентом, необходимым для реализации определенной стратегии (полагая, что такая существует), компонентом, который имеет смысл использовать либо потому, что предыдущие действия потерпели провал, либо когда жесткая сила рассматривается как дополнительная к полному спектру возможностей. ${ }^{51}$

«Когда» подразумевает наличие концептуального сдвига. Действительно, президент Обама очевидно рассматривает применение силы через линзу понимания этого вопроса в смысле Клаузевица, для которого война является продолжением политики, а не самой политикой. Он вознамеривается позиционировать военные действия на периферии континуума, где дипломатия, подкрепленная многосторонностью, занимает самое большое место. В соответствии с этим подходом, сила есть последняя возможность, а не возможность, к которой можно прибегнуть на более ранних этапах просто для того, чтобы обеспечить Соединенным Штатам более выгодную позицию в любых переговорах.

нием не настраивать ливийцев против НАТО. Такая степень нюансирования никогда раньше не наблюдалась в операциях с участием американский войск. Интервью с пилотами НАТО, проведенные автором, ноябрь 2011.

49 "Non-leader of the Free World," New York Post (18 March 2011).

50 Президент Барак Обама, речь в Страсбурге, Франция, 3 апреля 2009; доступно на: www.whitehouse.gov/the_press_office/Remarks-by-President-Obama-at-Strasbourg-TownHall.

51 Национальная стратегия безопасности Соединенных Штатов от 2010 года подчеркивает репозиционирование вооруженных сил как инструмент, в отличии от версии 2002 года; версия 2010 доступна на: http://www.whitehouse.gov/sites/default/.../national_security_ strategy.pdf. 
«Как» поднимает вопрос о характере военного участия, которое предстоит проектировать и проводить. Для этого требуется, чтобы политический лидер знал природу войны, в которую он собирается ввязаться. Отсутствие такого понимания как предварительного условия для принятия решения об использовании силы может иметь драматические последствия. ${ }^{52}$ Следовательно, возникает требование, чтобы президент США имел собственный взгляд на военную область. Институциональный аутсорсинг военной монополии на использование военной силы не является извинением не понимать того, как это делается. Эффективно выполняя свои обязанности Главнокомандующего, президент Обама не трубит публично об использовании силы, а вместо этого мудро ищет способы повышения ее эффективности, ${ }^{53}$ в частности, позволив массированное использование беспилотников и целевую ликвидацию лиц, увеличивая ресурсы разведки, хотя он и использует гораздо менее агрессивный словарь. ${ }^{54}$

\section{... которое требует Sine Qua Non рамки, чтобы привело к успеху}

Процедура принятия решения использовать жесткую силу оказывает влияние на результат. Она является сочетанием консенсуса внутри политического руководства и соответствующей профессиональной консультации военных. Президент Обама должен был приложить немалые усилия для того, чтобы политическое сообщество приняло способ, с помощью которого он прибегает к использованию силы, так же как и причины для ее применения, отличные от тех, что традиционно

52 «Первым, верховным, с наиболее далеко идущими последствиями актом суждения, который государственный деятель и командующий должен исполнить, это определить посредством этого теста тип войны, в которую он ввязывается; не принимая ее за что-то другое и не пытаясь превратить ее во что-то другое, что-то чуждое ее природе. Это и есть первый и наиболее глубокий из всех стратегических вопросов». Carl Von Clausewitz, On War, trans. Michael Eliot Howard and Peter Paret (Princeton, NJ: Princeton University Press, 1989), 88-89.

53 Michael C. Dorf, "The 'Obama Doctrine': The Wisdom and Lawfulness of the President's Take-No-Prisoners Approach,” Justia.com (24 October 2011); доступно на: http://verdict.justia.com/2011/10/24/the-obama-doctrine. See also Roger Cohen, "Doctrine of Silence," The New York Times (28 November 2011).

54 Greg Miller, "Pentagon Establishes Defense Clandestine Service, New Espionage Unit," Washington Post (23 April 2012); available at http://www.washingtonpost.com/world/ national-security/pentagon-creates-new-espionage-unit/2012/04/23/gIQA9R7DcT_story.html. Смотри так же: James Bamford, “The NSA Is Building the Country's Biggest Spy Center (Watch What You Say)," Wired.com (15 March 2012); доступно на: www.wired.com/ threatlevel/ 2012/03/ff_nsadatacenter.

В соответствии с правым мозговым центром, фондом «Херитидж фаундейшн», «Обама ссылается на проблему терроризма на 68 процентов реже, чем это делал Буш. Он сократил ссылки на средства массового уничтожения на 91 процент. Но он говорит о демократии на 74 процента реже, чем Буш, и о свободе на 92 процента реже». Nicholas Krueger, "The 2010 National Security Strategy, By the Numbers," The Foundry Blog, at Heritage.org (19 August 2010). 
принимались. ${ }^{55}$ Некоторые члены военного сообщества, возможно, имеют свое мнение относительно этих решений, но по понятным причинам их возражения находят выражение в более дискретной манере ${ }^{56}$ Однако, президент США пользовался особой свободой действий в фарватере событий от 9/11 - по крайней мере в рамках политического контекста США. Хотя и уничтожение Усамы Бен Ладена было исполнено при полном согласии тех людей из политического и военного мира США, которые были в него вовлечены, и было встречено с большим удовлетворением, это не означает, что и в будущих подобных операциях всегда будет так. $^{57}$ В таких случаях, будет нужно, чтобы члены Конгресса культурологически были склонны поддержать новый подход Обамы. Без сомнения, для достижения необходимого уровня общего понимания потребуется время.

Дополнительно к этому военные должны обеспечить соответствующую консультацию и их должны услышать, что ранее не всегда имело место. ${ }^{58}$ Можно задаться вопросом, не является ли назначение генерала Петреуса главой ЦРУ отражением перекрывающихся миссий гражданской разведки, военной разведки и агентств безопасности, и необходимости в более глубокой координации. Прежде всего, это обеспечивает бывшему военному лидеру лучшую платформу для предоставления консультаций политическому руководству. И на последнем месте, это иллюстрирует желание Обамы сформировать благоприятную среду, в которой он сможет обсуждать и принимать решения о соответствующем использовании силы.

Джоузеф Най писал: «Необходимая и желательная мягкая сила произрастает из культуры, ценностей и политики. Они предполагают соответственно, что необходимая культура является привлекательной для других, что ее ценности и привлекательны, и не подрываются несоответствующими практиками; и на последнем месте, стратегии считаются вовлекающими в себя большинство людей и они вы-

55 Смотри: речь президента Барака Обамы «О состоянии союза» от 2012 года, доступно на: www.whitehouse.gov/state-of-the-union-2012.

Eli Lake, "The 9/14 Presidency," reason.com (6 April 2010); доступно на http://reason.com/ archives/2010/04/06/the-914-presidency.

58 «Любому будущему министру обороны, который посоветует президенту снова послать большую американскую армию в Азию, или на Ближний Восток, или в Африку, надо будет пройти медосмотр головы». Высказывание бывшего министра обороны Роберта Гейтса, когда он уходил со своего поста в июле 2011 года. Цитировано Бингом Уестом в: Bing West "Groundhog War: The Limits of Counterinsurgency in Afghanistan," Foreign Affairs 90:5 (September/October 2011): 163-171; доступно на: www.foreignaffairs.com/ articles/ 68133/bing-west/groundhog-war.

Президент Джордж У. Буш пренебрег подобным советом накануне инвазии в Ирак в 2003 году. Действительно, Центральное командование вооруженных сил США заявило в 1998 году, что для стабилизации Ирака будут необходимы как минимум 380000 солдат. Смотри: Lt. Col. Paul Yingling, “A Failure in Generalship,” Armed Forces Journal 144 (May 2007): 16-23; доступно на www.armedforcesjournal.com/2007/05/2635198. 
глядят легитимными в глазах других». ${ }^{59}$ Эта цитата дает нам краткое обобщение пунктов, которые президент Обама постоянно подчеркивает как часть необходимых рамок для активизирования позиции США в мире. ${ }^{60}$

\section{Заключение}

Если в течении всей истории США большинство национальных доктрин безопасности были ясно наименованы, были замечательно предсказуемыми и их легко было охарактеризовать a posteriori (задним числом), доктрина Обамы-все еще предполагаемая-остается непредсказуемой и следовательно, менее понятной для противников. Надо ли доктрину обязательно официально дефинировать, чтобы она была эффективной, остается под вопросом. Но независимо от отсутствия официальной дефиниции, и несмотря на повторяющийся припев хора критиков, действия Обамы внесли разнобой в ряды тех, кто привык ссылаться на четкие стратегии. По ходу действий, доктрина действительно помогла укрепить превосходство США. ${ }^{61}$

Президента Обаму регулярно обвиняли в том, что он слабый актор во внешней политике, или что он продолжает внешнюю политику администрации Буша другими средствами. В этом эссе была сделана попытка показать, что его доктрина является весьма неконформистской, поскольку он не продолжил действие утвержденного администрацией Буша права превентивно и в одностороннем порядке использовать вооруженную силу против потенциальных угроз Соединенным Штатам. Наоборот, оно показывает, что Обама стремился активизировать роль США в качестве глобального лидера более мудрыми, по крайне мере, решениями об использовании силы, часто вырабатываемыми в более многосторонних рамках. $^{62}$ Может быть Обама и согласен, что лидерство США все еще означает систематическое и повсеместное военное превосходство, но его доктрина уже не призывает к систематическому его использованию. Это утверждение раскрывает целый спектр нюансов. Далее, односторонность и принятие прямых массированных во-

59 Terence Casey, "Europe, Soft Power and Gentle Stagnation," Comparative European Politics Review 4 (2006): 402. Термин «мягкая сила» был введен Джозефом Най, младшим, в 1990 году и о нем вспомнили в 2002, когда критиковали склонность к односторонним действиям администрации Буша.

61 Clay Risen, “Obama's Non-doctrine Doctrine," The New York Times (26 August 2011); доступно на http://opinionator.blogs.nytimes.com/2011/08/26/obamas-non-doctrine-doctrine.

62 B Chris Good, "The Obama Doctrine: Multilateralism with Teeth," theatlantic.com (10 December 2009); доступно на: http://www.theatlantic.com/politics/archive/2009/12/the-obamadoctrine-multilateralism-with-teeth/31655. В дополнении, российский министр иностранных дел Сергей Лавров, относясь настороженно ко многим элементам Стратегии национальной безопасности от 2010 года, приветствовал сдвиг фокуса на многосторонность. Смотри: "Russia Has Objections over U.S. National Security Strategy," RIA Novosti (1 September 2010); доступно на: www.globalsecurity.org/wmd/library/news/usa/2010/usa100901-rianovosti01.htm. 
енных ангажементов в наши дни показали себя контрпродуктивными, более чем когда-либо. Чувство ответственности не делает Обаму человеком, нежелающим идти на риск, а скорее человеком, который осознает риски, в стране, где эти разные понятия намеренно путают. Не быть в состоянии понять разницу между этими понятиями является большим недостатком в наше время, насыщенное вызовами, когда изменчивые и непредсказуемые риски пришли на смену простым и ясным угрозам. В то же время, «более скромная внешняя политика не станет причиной ни для нестабильности, ни для упадка». ${ }^{63}$

Такая рамка в принципе отводит военным способностям вторичную роль, при которой использование жесткой силы рассматривается как последнее средство, а не как основной инструмент внешней политики. Это не подразумевает и не отражает уменьшения внимания к вооруженным силам, но требует более тонкого использования, которое во все большей степени является вызовом для их эффективности. В конечном счете, вследствие примата политики, о самом Обаме будут судить не только по тому как он формирует вооруженные силы, но и по тому, как он решает их использовать. Пока же некоторые интеллигентные решения начали прокладывать дорогу к активизации роли США в качестве глобального лидера, избегая напрасного растрачивания энергии, когда дипломатия и умеренное использование военной мощи оказываются достаточными для облегчения кризисов. ${ }^{64}$

Будет ли доктрина безопасности Обамы сочетаться адекватно с прогрессом в таких областях как образование, экономика и культура, для того чтобы Соединенные Штаты действительно достигли прочного глобального лидерства, еще предстоит увидеть, и это может быть предметом дальнейшего исследования. Что бы ни случилось, переизбрание Обамы даст ему возможность вписать еще одну успешную доктрину в анналы безопасности США, доктрину, которая позволит США доминировать и в новом веке, полагая, что люди, принимающие ключевые решения, сохранят открытость ума и не будут искушены каким-нибудь типом фатализма.

63 Joseph M. Parent and Paul K. MacDonald, “The Wisdom of Retrenchment: America Must Cut Back to Move Forward," Foreign Affairs 90:6 (November/December 2011): 32-47; доступно на http://www.foreignaffairs.com/articles/136510/joseph-m-parent-and-paul-k-macdonald/thewisdom-of-retrenchment.

${ }^{64}$ Смотри: Graeme P. Herd, Great Powers and Strategic Stability in the $21^{\text {st }}$ Century (London: Routledge, 2010). 


\section{Литература}

"Des troupes saoudiennes à Bahrein, les chiites parlent de guerre." L'Express (2011).

"Doctrine of Silence." The New York Times (2011).

"Israel's siege mentality." The Economist (2010).

Bamford, James. The NSA Is Building the Country's Biggest Spy Center (Watch What You Say). Wired.com, 2012.

Boyle, Michael. "Obama: 'Leading from Behind' on Libya." The Guardian (2011).

Brzezinski Assesses Obama's Foreign Policy. National Public Radio, 2009.

Casey, Terence. "Europe, Soft Power and Gentle Stagnation." Comparative European Politics Review 4, no. 402 (2006).

Clinton, Hillary. Israeli Settlements 'Illegitimate'., 2011.

Clinton, Hillary. Israeli Settlements Condemned by Western Powers. BBC News, 2011.

Coates, A.J.. The Ethics of War. Manchester and New York, 1997.

Cohen, Tom. Obama Tells Families of 9/11 Victims that 'Justice has been done'. CNN Politics , 2011.

Counterinsurgency: The U.S. Army Field Manual. Washington, D.C.: Department of the Army, 2006.

Davis, Lt. Col. Danie. "Truth, Lies and Afghanistan - How military leaders have let us down." Armed Forces Journal (2012).

Dempsey, Gen. Martin E.. "Building Critical Thinkers: Leader Development Must Be the Army's Top Priority." Armed Forces Journal 148:7 (2011): 12-15.

Donnelly, Thomas, Phillip Dur, and Andrew F. Krepinevich, Jr.. "The Future of U.S. Military Power: Debating How to Address China, Iran, and Others." Foreign Affairs (2009).

Dorf, Michael C.. The 'Obama Doctrine': The Wisdom and Lawfulness of the President's Take-No-Prisoners Approach. Justia.com, 2011.

Gates, U.S. Defense Se. "2008 National Defense Strategy." Small Wars Journal (2008).

Goldberg, Jeffrey. "Obama to Iran and Israel: ‘As President of the United States, I Don’t Bluff'." The Atlantic Monthly (2012).

Good, Chris. The Obama Doctrine: Multilateralism with Teeth. theatlantic.com, 2009.

Hanson, Victor Davis. The President's Chosen Weapon. Philadelphia Inquirer, 2011. 
Hart, Liddell. Lawrence of Arabia. Boston: Da Capo Press, 1989.

Henty, George Alfred. For Name and Fame; or, Through Afghan Passes. London: Blackie \& Son, 1886.

Herd, Graeme P.. Great Powers and Strategic Stability in the 21st Century. London: Routledge, 2010.

Jackson, David. "Obama: Afghanistan Troop Withdrawal Process to Start Next Year USA Today." (2010).

Jaulmes, Adrien. "L’UE appelle à enrayer la colonisation en Cisjordanie." Le Figaro (2012).

Jones, Seth G.. Counterinsurgency in Afghanistan . Santa Monica: CA: RAND Corporation , 2008.

Kagan, Robert. Of Paradise and Power: America and Europe in the New World Order. New York: Alfred Knopf, 2003.

Kennedy, John F.. President John F. Kennedy's speech at West Point on 6 June 1962., 2009.

Kretchik, Walter E.. U.S. Army Doctrine: From the American Revolution to the War on Terror. Lawrence, KS: University Press of Kansas, 2011.

Krueger, Nicholas. The 2010 National Security Strategy, By the Numbers. The Foundry Blog, at Heritage.org, 2010.

Lake, Eli. The 9/14 Presidency. reason.com, 2010.

Michael, Ethan Bronner, and Michael Slackman. "Saudi Troops Enter Bahrain to Help Put down Unrest." New York Times (2011).

Michta, Andrew A.. "NATO’s Last Chance." The American Interest 6:5 (2011).

Miller, Greg. "Pentagon Establishes Defense Clandestine Service, New Espionage Unit." Washington Post (2012).

Morgan, David. Gates Criticizes NATO: How Much Does U.S. Pay?. CBS News, 2011.

Nagl, John A.. Learning to Eat Soup with a Knife: Counterinsurgency Lessons from Malaya and Vietnam. Chicago: University of Chicago Press, 2005.

Non-leader of the Free World. New York Post, 2011.

Obama, President Barack. President Barack Obama Speech in Strasbourg, France., 2009.

Panetta: U.S. Military Can't Make up NATO Shortfalls. msnbc.com , 2011.

Parent, Joseph M., and Paul K. MacDonald. "The Wisdom of Retrenchment: America Must Cut Back to Move Forward." Foreign Affairs 90, no. 6 (2011): 32-47. 
PERRY, MARK. "False Flag." Foreign Policy (2012).

President Barack Obama's 2012 State of the Union speech., 2012.

Record, Jeffrey, and Andrew W. Terrill. Iraq and Vietnam: Differences, Similarities and Insights. Carlisle, PA: Strategic Studies Institute of the U.S. Army War College, 2004.

Ricks, Thomas E.. Fiasco: The American Military Adventure in Iraq. New York: Penguin, 2006.

Risen, Clay. "Obama’s Non-doctrine Doctrine." The New York Times (2011).

Roberts, Veronica. General McChrystal Fired. Allvoices.com, 2010.

Romeo, Lisa. Etats-Unis et Arabie saoudite : les liens du pétrole de 1945 à nos jours . Les clés du Moyen-Orien, 2012.

Roubini, Nouriel. Middle East Turmoil and Contagion: A Geoeconomic Tsunami for the Global Economy. Roubini Global Economics , 2011.

Russia Has Objections over U.S. National Security Strategy. RIA Novosti, 2010.

Sanger, David E., and Peter Baker. "New U.S. Security Strategy Focuses on Managing Threats." New York Times (2010).

Sims, Christopher, Fernando Luján, and Bing West. "Both Sides of the COIN: Defining War After Afghanistan." Foreign Affairs (2012).

Special Ops now Defines the Pentagon's Expanding Wars. Global Research, 2012.

The United States' National Security Strategy 2010., 2010.

Traub, James. "A Moral Adventure - Is Barack Obama as much of a foreign-policy realist as he thinks he is?" Foreign Policy (2011).

von Clausewitz, Carl. Carl von Clausewitz On War. Princeton, NJ: Princeton University Press, 1989.

West, Bing. "Groundhog War: The Limits of Counterinsurgency in Afghanistan." Foreign Affairs 90:5 (2011): 163-171.

Wigglesworth, Robin, and Simeon Kerr. "Ahmadinejad Condemns Foreign Troops in Bahrain." Financial Times (2011).

Yingling, Lt. Col. Paul. "A Failure in Generalship." Armed Forces Journal 144 (2007): 16-23. 